\title{
MASTER
}

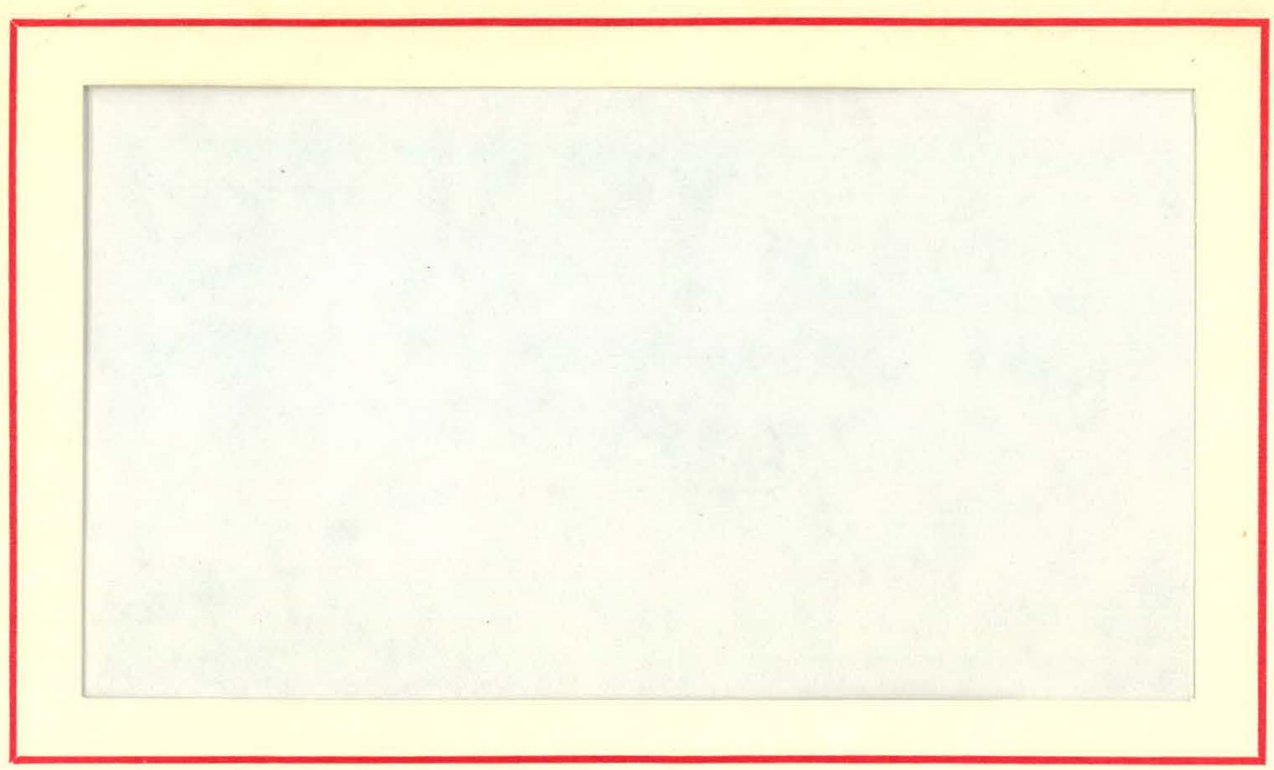

\section{TEMPLE UNIVERSITY}

OF THE COMMONWEALTH SYSTEM OF HIGHER EDUCATION

DEPARTMENT OF PHYSICS

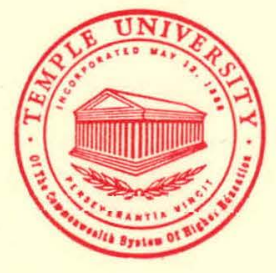

Philadelphia, Pennsylvania 


\section{DISCLAIMER}

This report was prepared as an account of work sponsored by an agency of the United States Government. Neither the United States Government nor any agency Thereof, nor any of their employees, makes any warranty, express or implied, or assumes any legal liability or responsibility for the accuracy, completeness, or usefulness of any information, apparatus, product, or process disclosed, or represents that its use would not infringe privately owned rights. Reference herein to any specific commercial product, process, or service by trade name, trademark, manufacturer, or otherwise does not necessarily constitute or imply its endorsement, recommendation, or favoring by the United States Government or any agency thereof. The views and opinions of authors expressed herein do not necessarily state or reflect those of the United States Government or any agency thereof. 


\section{DISCLAIMER}

Portions of this document may be illegible in electronic image products. Images are produced from the best available original document. 


\title{
DOE/ER/03539-.TI
}

\section{EXPERIMENTAL INVESTIGATIONS IN PARTICLE PHYSICS}

\section{AT INTERMEDIATE ENERGIES}

\author{
C00-3539-16 \\ Progress Report
}

For December 1, 1980 to November 30, 1981

L. B. Auerbach, V. L. Highland, W. K. McFarlane

Physics Department, Temple University

Philadelplica, PA 19122

Ju1y, 1981

Prepared for

THF, II. S. DEPARTMENT OF ENERGY

(Division of High Energy and Nuclear Physics)

UNDER CONTRACT NO. DE-AC02-76ER03539

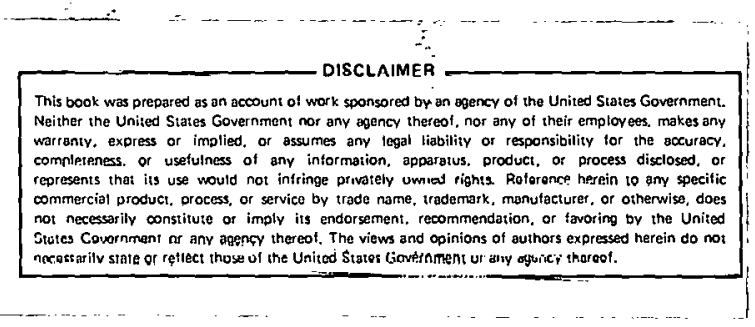

DISTRIBUTIOY OF THIS BOCUHE⿰HT IS UHLLIAITED

MGW 
s

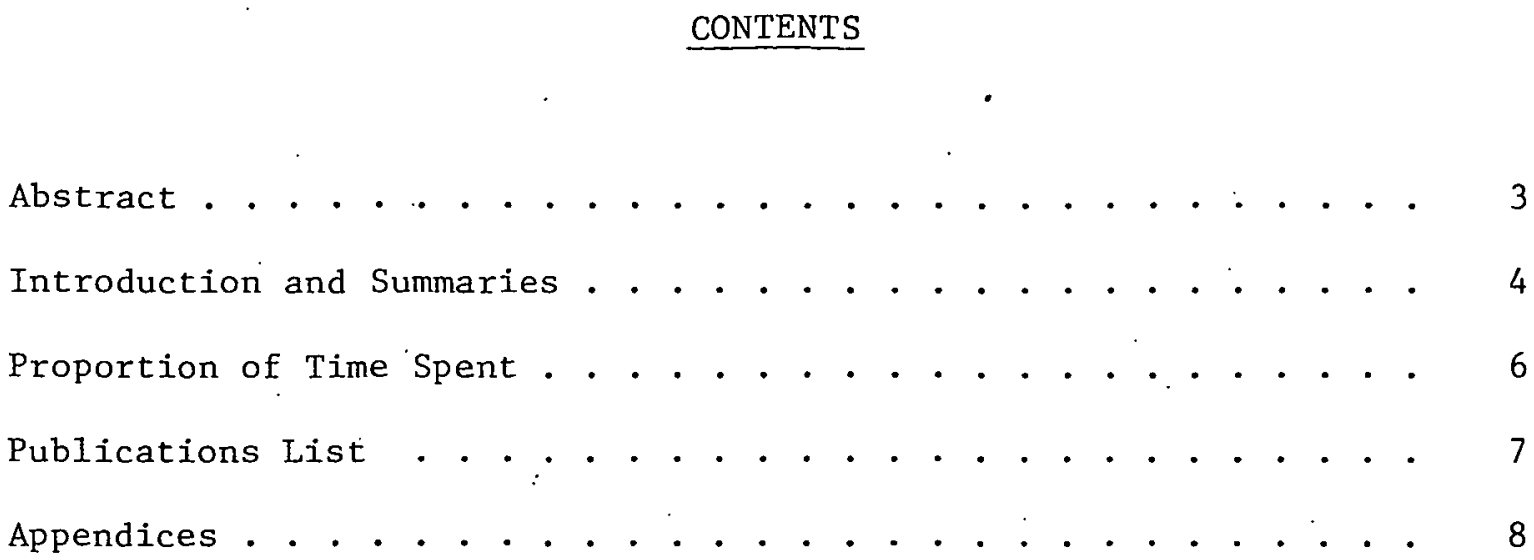

1. Search for structure in the low-energy $\bar{p} p$ annihilation cross section

2. Preliminary report on a new pion-beta-decay experiment

This report was prepared as an account of, work sponsored by the United States Government. Neither the United States nor the United States Department of Energy, nor any of their employees, nor any of their contractors, subcontractors, or their employees, makes any warranty, express or implied, or assumes any. legal liability or responsibility for the accuracy, completeness or usefullness of any information, apparatus, product, or process disclosed, or represents that its use would not infringe privatcly owned righte. 
Progress Report for Period December 1, 1980 - November 30, 1981.

For DOE Contract No. DE-AC02-76ER03539

\begin{abstract}
During this time we have completed data-taking on the pion-beta-decay measurement and made substantial progress in its analysis. Also we are nearing completion of the low-energy pp annihilation cross section experiment. Planning for a new pi-zero-to-three-gamma experiment at LAMPF is complete. The proposal to use the LEAR facility at $\mathrm{EERN}$ for further $\bar{p}$ p work has been approved. We have ... made some contributions to the preparation of a neutrino experiment proposal at LAMPF.
\end{abstract}


Introduction

Our program of experiments can be divided into three groups: rare pion decays, nucleon-nucleon scattering and nucleon-antinucleon interactions at low energy. The common factor in this work is the examination of the properties of three of the four basic interactions: weak and electromagnetic (rare pion decays) and strong (NN and $\bar{N} N$ interactions). The $\bar{N} N$ work can throw light both on the nucleon-nucleon interactions by exploiting the symmetry properties of $\mathrm{NN}$ potentials or forces and on the fundamental quarkquark interactions by examining the details of the $\mathrm{NN}$ interactions. We have also begun work on a neutrino experiment.

In the paragraphs below we summarize the results of our work so far. These published papers which have not already been submitted as technical reports are included as appendices.

Rare Pion Decays

In this period we have completed data-taking on the pion-beta-decay experiment. It was successful in that we saw a clear signal with only a small background. We were not however able to run at full beam intensity because of backgrounds and will have a final sample of only about 1200 events, and so we can do no better than a $3 \%$ measurement. We will study our results and see whether a new proposal can be made for an experiment with improved backgrounds. A preliminary report is included as Appendix 1. We are preparing a new proposal to do the $\pi^{\circ} \rightarrow-3 \gamma$ measurement using the Crystal Box. If our proposal meets with the approval of the group constructing this detector, it will be submitted to the winter meeting of the LAMPF PAC. 


\section{Nucleon-Nucleon Scattering}

We have no active proposals for more data-taking in this area. Over the last two years, the PAC first postponed then cancelled the continuation (at other energies) of experiments 193 (ṇp scattering) and 124 (single pion production in pp scattering). We are making plans therefore to publish the single-energy ( 800 Mev) data which.we do have (including the nd/pd comparison of experiment 279). This is very disappointing because the scientific value of our efforts has been largely negated as a result.

It is only a little more effort to run a proven apparatus at different energies, but the value of measurements at several energies with the same apparatus is great, while a single-energy measurement'is unlikely to be given much weight in future analyses:

This effort was a collaboration with the University of New Mexico and LANL.

\section{Antiproton Work}

Analysis of the $\bar{p}$ d experiment (Exp. 701 at BNL) is proceeding (primarily at UNM and U. C. Irvine); we expect results in the next year or so. The analysis of the $\bar{p}$ p annihilation off-shoot of this experiment (searching for the ' $S$ ' meson) is almost complete; results have been published in Physical Review as a Rapidd Communication (Ref. 3 and Appendix 2).

The experiment on $\bar{p} p$ to neutral vees in collaboration with Rutgers and BNL is essentially a failure: the analysis of the cylindrical spark chammbers proved to be too difficult. As a result, only about 100 events at each energy. (1-3 GeV/lc) will be availlable, not enough to make a real combination, although a theșis (from Rutgerș) will be written on this work. 
Our proposal, to CERN with Michigan State, U.C. Irvine, and the University

of New Mexico has been approved by the CERN Research Board, and we haye been joined by a group from Athens University (Greece) led by A. Apostolakis: Several visits have been made to CERN to work out details of various kinds in preparation for a run in 1983. We will make final designs for various parts of the apparatus, and purchase some items.

Neutrino Experiment

We have been invited to join the LANL effort led by T. Dombeck to design a neutrino detector and facility (LAMPF Experiment 638). This is a collaboration of LANL, U. of Maryland, U. C, Riverside, University of New Mexico and now Temple. We have taken responsibility in the areas of the scintillator detector and the data-acquisition system. We will help prepare the proposal to DOE for this experiment: Proportion of time spent by Investigators

Dr. McFarlane devoted one-third time to the project during the academic year and full time for three summer months, Dr, Highland and Auerbach devoted one-third time during the academic year and full time for two summer months.

F. Gaille and E. Jastrembski (Research Assistants) devoted $100 \%$ of their time for 12 months; A. Waby worked on the project for two summer months. 
Publications list for DOE Contract No. DE-AC02-76ER03539 for 1980-81

1). Search for Structure in Nucleon-antinucleon Interactions Near Threshold W. K. McFarlane), Proc. Workshop on Nuclear and Particle Physics at Energies up to $31 \mathrm{GeV}:$ New and Future Aspects, Los Alamos, Jan 5-8, 1981, LANL Report LA-8775-C, p. 319.

2) Preliminary Report on a New Pion Beta Decay Measurement (V. L. Highland), Proc. Workshop on Nuclear and Particle Physics at Energies up to $31 \mathrm{GeV}$ : New and Future Aspects, Los Alamos, Jạ 5-8, 1981, LANL Report LA-8775-C, p. 94 .

3) Search for Structure in the Low Energy pp Annihilation Cross Section (E. Jastrzembski, N. Haik, W. K. McFarlane, M. A. Mandelkern, D. C. Schultz, C. Amsler, C. C. Herrmann, and D. M. Wolfe) Physical Review D, vol. 23, p. 2784 (1981).

4) Branching Ratios for Stopped Pions in Deuterium(V. L. Highland, M. Salomon, M. D. Hasinoff, E. Mazzucato,D. F. Measday, J.-M. Poutissou, and T. Suzuki), accepted for publication in Nuclear Physics, also C00-3539-14. 


\section{Appendix 7}

Submitted to 9-ICOHEPANS, Versailles,

France, July 5-12th, 1981

PRELIMINARY REPORT ON A NEW PION BETA DECAY EXPERIMENT*

by

V. L. Highland, W. K. McFarlane, L. B. Auerbach,

F. C. Gaille, E. Jastrzembski

Temple University

and

R. J. Macek, G. E. Hogan, R. E. Morgado, R. D. Werbeck

J. C. Pratt, C. M. Hoffman, F. Cverna

Los Alamos National Laboratory

The conserved vector current hypothesis (CVC) ${ }^{\text {? }}$, a cornerstone of the unified theory of electromagnetic and weak interactions, provides a precise prediction for the branching ratio of the pion beta decay reaction $\pi^{+} \rightarrow \pi^{0} \mathrm{e}^{+} \nu$. The predicted ratio is $1.045 \times 10^{-8}$ with an uncertainty of $0.5 \%$ due to errors in the pion masses and an additional $1 \%$ uncertainty due to the electromaynetic corrections. The most precise existing experiment is that of Depommier et al. ${ }^{2}$ who found a branching ratio of $1.00+0.08 \times 10^{-8}$

This experimental result is consistent with the theory within the errors, but it is clearly very desirable to improve the experimental precision so that it approaches that of the theory. Also, since all previous experiments used the same technique (of stopping pions), it is possible that similar systematic errors could have given spurious agreement with the theory. We have just completed taking data on a new pion beta decay experiment, using a new technique with different types of systematic error. Here we present a preliminary report on the experiment to indicate the extent and quality of the data obtained.

In contrast to the previous experiments done with stopping pions, this one observes decays in flight of a $400-\mathrm{MeV}: \pi^{+}$bediil * Supported in part by the U.S. Department of Energy 
in the $\mathrm{P}^{3}$ East Channel at LAMPF. The massive $\pi^{0}$ from the $\pi^{+}$ beta decay has essentially the same momentum as the $\pi^{+}$, and we detect the two energetic $\gamma$ rays from the $\pi^{0}$ decay. It is necessary to use a very intense beam of $2 \times 10^{8}+/ \mathrm{s}$. Figure 1 shows our apparatus.

In order to avoid background from pion charge exchange, the decays take place in a vacuum tank at $2 \times 10^{-7}$ torr. There is an intense flux of secondary $\mu^{\prime \prime} s$ from decay of the $\pi$ 's. The beam is collimated and the detectors located so that they cannot see these $\mu$ 's. The last collimator is toroidally magnetized iron in order to reduce $\mu$ scattering out of the collimator. This magnetization of the collimator allowed us to run at a beam rate three time more intense than would otherwise have been tolerable. In order to monitor this intense beam we used ion chambers and $\pi \rightarrow \mu \nu$ detectors downstream of the experiment.

The $\gamma$ rays were detected the Pb-glass counters of the LAMPF $\pi^{0}$. spectrometer, using $X Y$ scintillation hodoscopes for position definition. The time and energy calibrations of the detectors were frequently checked by swinging a $\mathrm{CH}_{2}$ target inside the vacuum tank into the beam and producing $\pi{ }^{6} s$ by charge exchange.. As a final calibration, the entire tank was filled with $\mathrm{H}_{2}$ gas and the bedili changed to "

In Fig. 2 is given the spectrum of the sum of the two $r$-ray energies after selecting on prompt timing of each $\gamma$ with respect to the beam RF and making some low energy. cuts in each of the counters. There is a clean well-defined peak with the expected resolution. To verify the pion-beta decay identification one can look at the transverse momentum and coplariarity. These variables show distinct peaks as expected for beta decay. These variables provide additional potential cuts, but it will not be necessary to make any but very mild cuts to further clean up the event selection. 
The events shown in Fig. 2 represent very nearly our final sample. A later analysis gave a total of $1180 \pm 70$ events, where the error on the number of events is estimated on the basis of uncertainties in the selection process, which we expect to refine. Including uncertainties in the incident pion flux, detection efficiency and various other corrections; we quote a preliminary result of $(1.02 \pm 0.06) \times 10^{-8}$ for the branching ratio..

We expect to improve our estimates of uncertainties and to be able to produce a number with a quoted error determined mainly by the statistics ( $i . e$ : at about the $4 \%$ level), and thus to have a significantly better value for the branching ratio of pion beta decay, although still not with a precision approaching that of the theory.

\section{REFERENCES}

1. R. Féynman and M. Ge11-Mann, Phys. Rev. 109, 193 (1958).

2. P. Depommier, J. Duclos, J. Heintze, K. Kleinknecht, H. Rieseberg, and V. Soerge T, Nucl. Phys. B4, 189 (1968). Also see this for a discussion of previous experiments. 


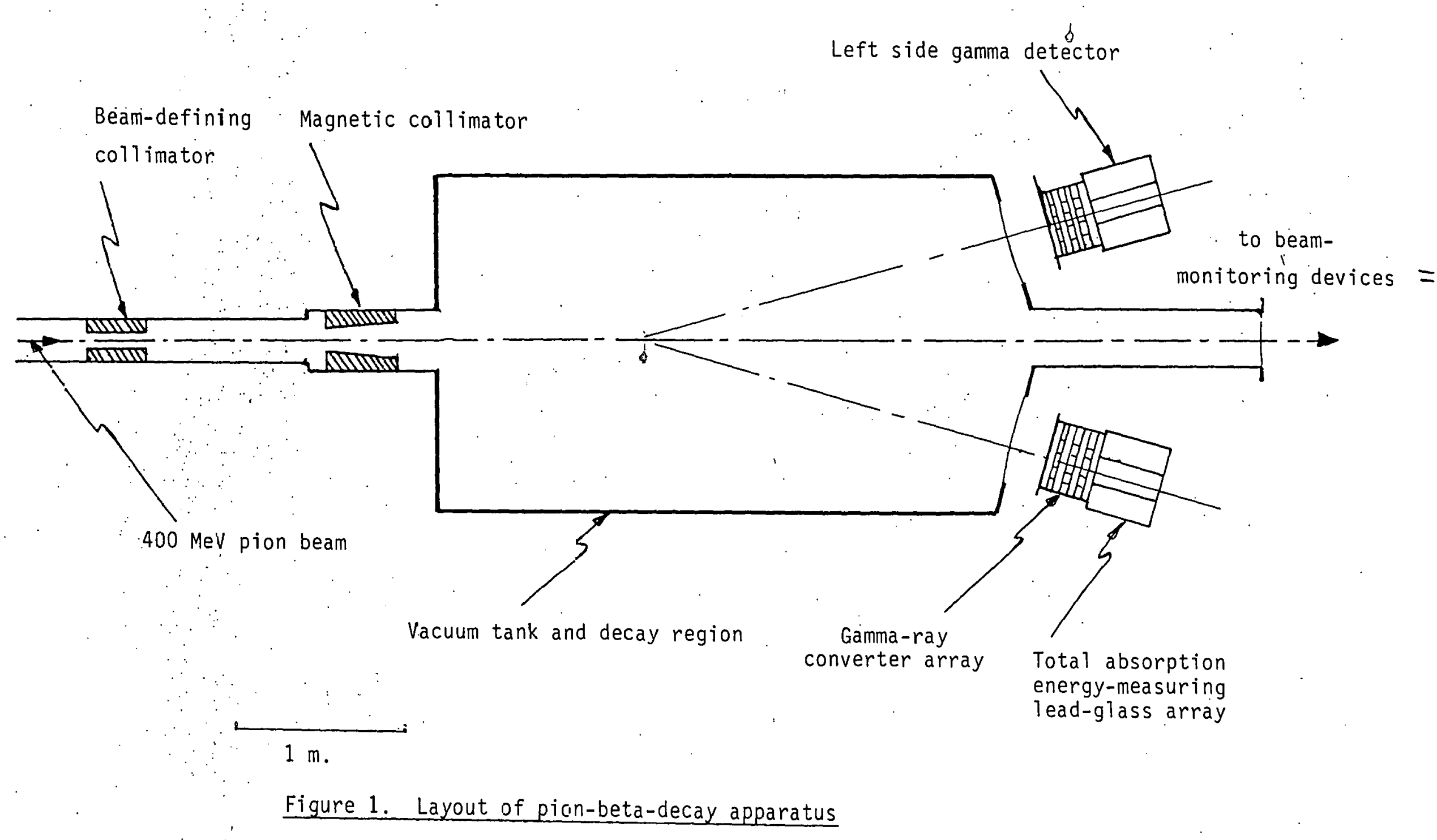




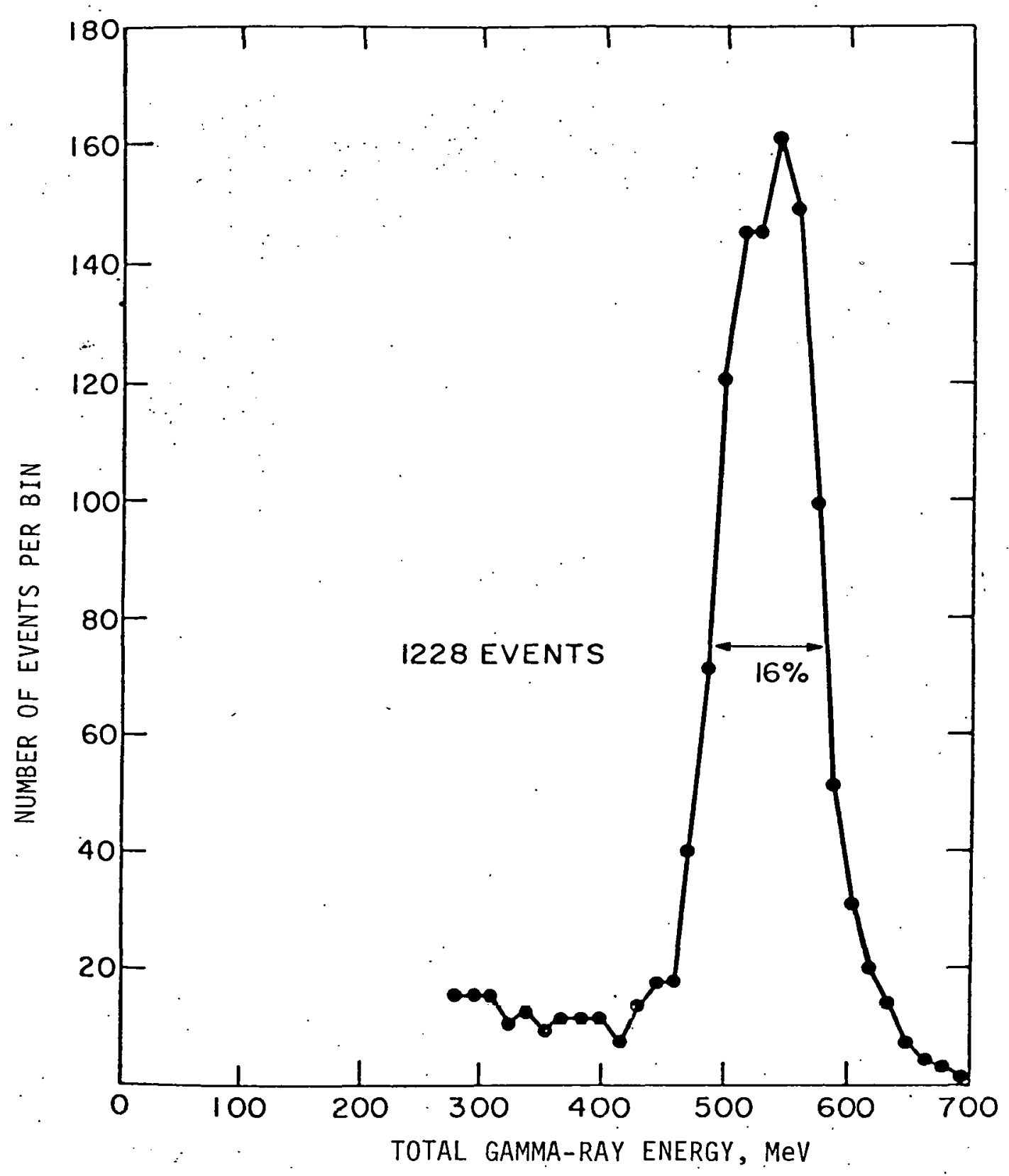

Figure 2. Distribution of the sum of the energies of coincident pairs of gamma-rays. 